\title{
Development of a safe drug administration assessment instrument for nursing students*
}

\author{
Karen Domínguez Cancino ${ }^{1,2}$ \\ (D) https://orcid.org/0000-0002-4264-8476 \\ Marisol Arias ${ }^{1}$ \\ (1) https://orcid.org/0000-0003-2434-9488 \\ Erika Caballero ${ }^{3}$ \\ (1D) https://orcid.org/0000-0003-0924-3896 \\ Eliana Escudero ${ }^{1}$ \\ (D) https://orcid.org/0000-0001-7480-1992
}

* Suported by Universidad Finis Terrae, Chile - Grant \# 03/2016.

1 Universidad Finis Terrae, Escuela de Enfermería, Santiago, Chile.

2 Universidad María Auxiliadora, Facultad de Salud, Peru.

${ }^{3}$ Universidad Autónoma de Chile, Chile.
Objective: to determine the content and face validity of a safe drug administration assessment instrument for nursing students. Method: quantitative, descriptive study. The literature on medication errors made by students was analyzed, and an instrument was developed using the Architecture of Integrated Information Systems and the Work Breakdown Structure. Face validity was analyzed using the nominal technique, with experts in education, management, research and/or clinical practice. Results: nine experts participated in the validation process, which resulted in an instrument containing 8 sub-processes and 58 items, adjusted to the simulation environment and to clinical practice. Conclusion: the instrument may be used for the evaluation of safe drug administration by nursing students, especially in a simulation environment.

Descriptors: Nursing Research; Medication Errors; Education, Nursing; Patient Safety; Simulation Training; Guideline Adherence.

\section{How to cite this article}

Cancino KD, Arias M, Caballero E, Escudero E. Development of a safe drug administration assessment instrument for nursing students. Rev. Latino-Am. Enfermagem. 2020;28:e3246. [Access DOI: http://dx.doi.org/10.1590/1518-8345.2989.3246. 


\section{Introduction}

Although 18 years have passed since the publication of the Institute of Medicine's (IOM) "To Error is Human"(1), preventable adverse events remain an unresolved issue, and are a cause of major concern today(2). Adverse events may reach values close to $10 \%$, with greater prevalence of those related to drug use, anesthesia and surgery, and hospital infections ${ }^{(3)}$. Drug use errors are associated with somewhere between 3 and $6 \%$ of hospital admissions, 30 to $40 \%$ of which are the result of avoidable errors ${ }^{(4)}$. A study in Chilean hospitals found a medical error rate of $1.2 \mathrm{x}$ 1,000 , which is considered high. These errors occurred in medical services and Critical Patient Units, the most frequent being related to drug administration (47\%) and dispensation $(27 \%)^{(5)}$.

Prevention strategies and the development of an event notification culture are the pillars to avoid such errors $^{(6)}$. Recognizing the causes of drug administration errors and implementing safety strategies before, during and after this process results in a significant increase in the quality of patient care(6).

Different studies have shown that nursing professionals play a crucial role in preventing medication errors in clinical practice ${ }^{(7-8)}$, as these correspond to the last barrier separating the patient from medication. Despite the acknowledgment of this fact, professionals are not properly trained in how to deal with errors, especially due to the relationship of these events with feelings of guilt, shame and limited scientific knowledge, as well as the fear related to ethical and legal responsibilities ${ }^{(7)}$. Given the responsibility of nursing professionals and the high prevalence of medication errors in clinical settings, especially those administered parenterally ${ }^{(9)}$, the Finis Terrae University's School of Nursing, as evidence of its high commitment to patient safety, used an information management system with care management indicators to develop a drug administration protocol(10-11) based on the available information on the subject $t^{(1,3-4,7-9,12-13)}$, applying the Architecture of Integrated Information Systems (ARIS) (14) and the Work Breakdown Structure (WBS) ${ }^{(15)}$. The purpose of the protocol is incorporating the processes of drug management, administration and dispensation, with their associated records, as a fundamental pillar in the training of students, emphasizing the concepts of safety and quality of health care. The protocol establishes 9 sub-processes, including safety breaks, that favor the safe administration of drugs: reassessment of prescription, evaluation, dispensation, transcription, preparation, administration, error reporting, follow-up and monitoring of therapeutic, side and adverse effects, and provision of information to the patient. This protocol has been applied throughout the course since 2016 .

At the international level, it is recognized that there are at least three steps in the drug administration process(14-15), varying between different countries, mainly due to legal conditions and the implementation of computerized processes, interventions aimed at making this process safer(16). In countries such as Chile, the nurse is responsible and involved in all stages of the process, either by performing, delegating or supervising these instances.

The aim of the present study was determining the face and content validity of a safe drug administration assessment instrument for nursing students.

\section{Method}

This was a quantitative, descriptive study, conducted at the School of Nursing under the project "Assessment of the impact of the safe drug administration protocol for nursing students one year after its implementation", with funding from an Annual Research Bidding Process (CAI) held by the Board of Research and Graduate Studies at the Finis Terrae University in 2017.

The study was carried out in two different phases, comprising the creation and validation of the instrument. In the creation phase, the safe drug administration protocol used in the School of Nursing was considered as base, consisting of nine sub-processes, each with a definition, a responsible party, aspects to verify, observations, records and safety breaks to prevent possible risk situations. For the instrument's creation, the indications for each sub-process were transformed into observable actions expected in the process of safe parenteral drug administration, performed in the simulation environment or in clinical practice, having as possible answers "yes", "no" and "not applicable". This process was carried out by one of the researchers and then revised and discussed with the others.

The second phase consisted in the instrument's face validation by the experts using the nominal group technique(17). Nationally prominent people in the fields of research, management, medical education and clinical simulation were contacted, as well as clinical professionals, both pediatric and adult, who worked 
in education and health institutions, both public and private, and who had conducted present or past teaching activities at the school, being thus familiar with the Institution's curriculum(18), totaling 17 experts.

An email containing an invitation letter was sent, along with a personal data survey, the safe drug administration protocol and the safe drug administration assessment instrument. Once the expert agreed to participate, he/she was asked to submit the personal data survey, containing information about his/her experience, graduate studies and publications in the above areas, also including an item concerning his/her coefficient of expertise ${ }^{(19-20)}$, used to decide whether the expert was qualified to carry out the process.

As indicated by the nominal technique, there was a remote and an in-person phase. In the remote phase, the experts were requested to send their assessment of the specific aspects, relevance and quality of the item. Relevance refers to the importance of including the item to measure the "safe drug administration" process, while quality refers to proper wording, and to whether the item is easy to understand and apply in different scenarios. A Likert-type scale was used to determine the level of agreement with each item, considering the categories "strongly disagree", "disagree", "neither agree nor disagree", "agree" and "strongly agree". In addition, a space for comments was provided at the end of each sub-process included in the instrument.

Once the information had been obtained, the data were revised by analyzing the experts' evaluations and agreement level, as well as the comments regarding each item, after which they were invited to attend an in-person session to unify the criteria.

For the development of the in-person session, a presentation was prepared in audiovisual media to allow discussing the relevance of the item's inclusion and the clarity with which it was exposed, in the case of aspects with at least one score in the categories "neither agree nor disagree", "disagree" and "strongly disagree". The items with scores in the categories "strongly agree" or "agree" were not considered, as there was no discrepancy in the analysis. The sessions were recorded and then transcribed verbatim for later analysis.

Subsequently, the instrument was applied by the evaluators, after the faculty had been trained in its application as well as that of the protocol, in a simulation environment built for a small group of students, two from the third year and two from the fourth year, with at least one year of experience with the protocol's application, to analyze the instrument's behavior in relation to the evaluation process commonly used at the school in high-stake instances taking place throughout the students' career $^{(18)}$. The objective was to test both regarding the realism of the clinical simulation scenario.

A low-fidelity simulation environment was built to test the instrument. Low-fidelity simulations correspond to a training activity wherein the professor guides and corrects the student in relation to a given technique ${ }^{(21)}$. The student is given prior instructions on how to carry out the learning experience (briefing), as well as ongoing feedback, allowing him/her to correct and improve his/her performance. The simulation lasted 10 minutes, and the evaluators observed it from behind a mirrored glass. The student was asked to prepare and administer a parenteral drug to control the patient's pain, after which he/she had 5 minutes to register the procedures performed. Each student was evaluated by two experts, who could ask the researcher general questions without showing their results to someone else so as not to influence other people's answers. In addition, they could suggest changes to the instrument based on what was observed in the scenario and on the ease of its application.

Regarding the ethical aspects, the four bioethical principles (non-maleficence, beneficence, justice and autonomy) and the criteria of Ezekiel Emanuel(22) were considered, in addition to the norms and laws applicable to research with human beings in the country. The experts signed an invitation letter, agreeing to participate in the research and ensuring the confidentiality of the research data. Additionally, the students who participated in the application of the instrument were asked to sign an informed consent form. The study was approved by the research ethics committee of the Finis Terrae University (Resolution No. 15/2017).

\section{Results}

The creation/validation of a standard observation instrument followed the analysis of the initial one by the researchers. An instrument with 9 sub-processes containing 63 items answered as either "yes", "no" and "not applicable" was obtained, each with a column in which the expert and/or evaluator could comment on the students' performance. 
Of the 17 experts contacted, 13 participated in the remote stage, and 9 attended the discussion session in person or via videoconference.

Characteristics of the experts: of the 13 participants, $92 \%$ were women, aged from 34 to 61 years old; $92 \%$ were nursing professionals, and $100 \%$ had graduate degrees, $40 \%$ had undergraduate degrees, and $85 \%$ had master's degrees. Most specialists were active in more than one area (research, management, medical education and clinical simulation). The average time of experience with safe drug administration was 8 years (values between 0 and 27 years).

Table 1 presents the coefficient of expertise globally. Of the experts, $92 \%$ actually met the criteria in terms of knowledge level and sources of arguments for validating the instrument. Those with expertise categorized as low were excluded.

Table 1 - Coefficient of expertise $(\mathrm{N}=13)$. Santiago, Chile, 2017

\begin{tabular}{lcccc}
\hline & Mean & Minimum & Maximum & Number (\%) \\
\hline $\begin{array}{l}\text { Knowledge level } \\
\begin{array}{l}\text { Sources of } \\
\text { arguments }\end{array}\end{array}$ & 0,72 & 0,3 & 0,9 & \\
$\begin{array}{l}\text { Final degree of } \\
\text { expertise }\end{array}$ & 0,85 & 0,5 & 0,9 & \\
$\begin{array}{l}\text { Category of the coefficient of expertise } \\
\text { Low }\end{array}$ & 0,45 & 0,95 & \\
Medium & & & $1(8,0 \%)$ \\
High & & $6(46 \%)$ \\
\hline
\end{tabular}

Discussion sessions: two sessions were held on different days of March, lasting 2 hours and 30 minutes. Using the presentation in audiovisual media, the answers of the experts were analyzed, focusing on the items with scores in the categories "do not agree or disagree", "disagree" and "strongly disagree", in relation to relevance and quality. During the discussion, the complexities of the process were addressed, along with the experiences of each of the participants. In addition, the wording required to make the instrument more comprehensible was analyzed, and some steps were limited due to the difficulty of measuring certain aspects in a single observation. It was decided to merge, limit or simplify some sub-processes and items, and the wording was adapted to actions deemed as easily observable in evaluation environments. In this phase, an instrument containing 8 sub-processes and 61 evaluation items was obtained.
After the instrument's application in the simulation environment, the evaluators suggested the removal of 3 items, as well as minor changes to the wording used.

The final instrument consisted of 8 sub-processes: reassessment of prescription, evaluation, dispensation, transcription, preparation, administration, error reporting, follow-up and monitoring, and provision of information to the patient, evaluated in 58 items. The sub-processes, items, and safety breaks are shown in Figure 1.

\begin{tabular}{|ll|}
\hline \multicolumn{1}{|c|}{ Sub-processes } & \multicolumn{1}{c|}{$\begin{array}{c}\text { Quantity of items and safety } \\
\text { breaks }\end{array}$} \\
\hline $\begin{array}{l}\text { Reassessment of drug } \\
\text { prescription }\end{array}$ & 10 items, 1 safety break \\
$\begin{array}{l}\text { Evaluation } \\
\text { Transcription to the medical } \\
\text { records (if applicable) }\end{array}$ & 1 item \\
$\begin{array}{l}\text { Drug Preparation } \\
\text { Administration of the medication } \\
\text { Error reporting (if applicable) }\end{array}$ & 14 items, 1 safety break \\
$\begin{array}{l}\text { Follow-up and monitoring of the } \\
\text { patient }\end{array}$ & 1 item \\
$\begin{array}{l}\text { Provision of information about } \\
\text { the treatment to the patient }\end{array}$ & 2 items \\
\hline
\end{tabular}

Figure 1 - Configuration of the final instrument. Santiago, Chile, 2017

\section{Discussion}

This research aimed to determine the face and content validity of a safe drug administration assessment instrument for nursing students. An instrument with 8 sub-processes was developed, including: reassessment of prescription, evaluation, dispensation, transcription, preparation, administration, error reporting, follow-up and monitoring of therapeutic, side and adverse effects, and provision of information to the patient, evaluated in 58 items, having been considered by experts and evaluators as easy to apply and transferable to clinical practice.

The use of judgment by experts as a strategy to validate instruments in the nursing field, especially processes involving observable actions, has been observed (23-27). The most frequently used technique is the Delphi method, which allows blindly obtaining information from experts in three rounds in order to estimate the final percentage of agreement(23-27). The participation of experts located in areas that are geographically more distant and the reduction of consensus-derived problems are seen as competitive advantages compared to the nominal group technique ${ }^{(28)}$. However, the first point was relatively remedied in this research, as the experts were allowed to participate in the different sessions via 
videoconferences. On the other hand, the assessment instrument was applied in a simulated environment, following the usual academic practices performed in our school, without considering a process for testing its reliability ${ }^{(23-27)}$.

Research shows that some of the reasons why safe drug administration protocols fail or have poor adherence are, on the one hand, related to poorly learned and highly ingrained professional practices ${ }^{(9)}$, and, on the other, due to the limited opportunities to train and acquire competence in this practice ${ }^{(29-30)}$. This justifies the implementation of instruments such as this in academic processes. Studies have associated simulation focused on skills with the development of safe health care practices(31-32). Review conducted in 2017 highlights the importance of training with simulation experiments(33). This review shows the improvements achieved by subjecting nursing professionals and students to learning experiences using this methodology, especially in relation to safe drug administration. Similarly, evidence from 2019 shows improvements in the results of the training of nursing professionals subjected to simulations, with promotion of very specific skills such as those associated with assessment and emergency ${ }^{(34)}$, supporting the performance of simulation-based interventions focused on different critical areas related to medication errors in the early stages of the professionals' training(35).

The strengths of the study include it being the first published initiative to standardize the drug administration process by identifying specific steps required to prevent nursing students from making medication errors. The instrument allows the assessment of competency and provision of standardized feedback. It was developed as a standardized technique to be used in the professionals' training, with the aim of ensuring the quality and safety of the process, both in simulation activities and clinical practice ${ }^{(36-37)}$. Training students in safety practices may lead to changes in the way things are done, as well as decrease the rate of adverse events in the future. Training and practice in clinical simulation favor the progressive and repetitive application of sub-processes until the achievement of a certain skill, also helping students reflect on and correct errors(38), benefits which have been tested for the teaching of safe drug administration(39). Studies show that students and professionals value the use of nontraditional strategies such as clinical simulation in the teaching and learning of certain habitual practices, like drug administration(40).

One of the weaknesses of the study is the fact that the instrument has no criterion and construct validity. This is related to the lack of other instruments to measure the process (concomitant) and of hard data on medication errors made by students (predictive), which poses a new challenge for the team to conduct further research and continue improving it.

On the other hand, during the validation process, it was difficult to obtain a consensus from the experts, due to the heterogeneity of opinions and lack of Chilean regulations on drug administration, which is line with what has been observed internationally.

Another difficulty that could be solved, but is still worth mentioning, is that there was a certain heterogeneity in the application of the protocol and assessment instrument in the simulated scenario, although the professors had been trained in it. This is partly due to the fact that the professors' training does not necessarily lead to competence in the performance of the simulation methodology ${ }^{(41)}$.

Studies such as this will enable undergraduate students to acquire skills in safe healthcare practices. The nursing faculty has the responsibility to generate strategies to reduce adverse events at the end of the process.

\section{Conclusion}

The instrument is in conditions of being used by the nursing faculty to evaluate the safe administration of medication by nursing students, especially in a simulation environment.

\section{References}

1. Makary MA, Daniel M. Medical error-the third leading cause of death in the US. BMJ. [Internet]. 2016 May 3 [cited Jul 11, 2019];353:i2139. Available from: http:// www.ncbi.nlm.nih.gov/pubmed/27143499

2. Cooper J, Williams $H$, Hibbert $P$, Edwards A, Butt A, Wood $F$, et al. Classification of patient-safety incidents in primary care. Bull World Health Organ. [Internet]. 2018 Jul 1 [cited Jul 11, 2019];96(7):498-505. Available from: http://www.ncbi.nlm.nih.gov/pubmed/29962552 3. Lancis-Sepúlveda ML, Asenjo-Araya C. Incidence of adverse events in a private hospital in Chile. Rev Calid Asist. [Internet]. 2014 Mar 1 [cited Jul 11, 2019];29(2):78-83. 
Available from: https://www.sciencedirect.com/science/ article/pii/S1134282X13001486?via\%3Dihub

4. Orser BA, Hyland S, David U, Sheppard I, Wilson CR. Review article: improving drug safety for patients undergoing anesthesia and surgery. J Can Anesth. [Internet]. 2013 feb [cited Jul 11, 2019];60(2):12735. Available from: https://link.springer.com/ article/10.1007/s12630-012-9853-y

5. Lara AC, Nieto JS, Vargas YS, Velasquez SM. Adverse drug event reporting system: a university hospital experience. Enferm Glob. [Internet]. 2014 Jan [cited Jul 11, 2019];13. Available from: http://scielo.isciii.es/ pdf/eg/v13n33/en_administracion1.pdf

6. Valencia MIB. Preventing errors in medication administration in anesthesia. CES Med. [Internet]. 2014 Dec [cited 2019 Jul 11]; 28(2): 307-12. Available from: http://www.scielo.org.co/scielo.php?script=sci_ arttext\&pid=S0120-87052014000200015\&Ing=en

7. Duarte SCM, Stipp MAC, Silva MM, Oliveira FT. Adverse events and safety in nursing care. Rev Bras Enferm. [Internet]. 2015 Feb [cited Jul 11, 2019]; 68(1): 144-54. Available from: http://www. scielo.br/scielo.php?script=sci_arttext\&pid=S003471672015000100144\&Ing=en.

8. Keers RN, Williams SD, Cooke J, Ashcroft DM. Causes of Medication Administration Errors in Hospitals: a Systematic Review of Quantitative and Qualitative Evidence. Drug Saf. [Internet] 2013 Nov [cited Jul 11, 2019];36(11):1045-67. Available from: https://www. ncbi.nlm.nih.gov/pmc/articles/PMC3824584/

9. Schilp J, Boot S, de Blok C, Spreeuwenberg P, Wagner C. Protocol compliance of administering parenteral medication in Dutch hospitals: an evaluation and cost estimation of the implementation. BMJ Open. [Internet]. 2014 Dec 30 [cited Jul 11, 2019];4(12):e005232. Available from: https://bmjopen.bmj.com/content/4/12/e005232 10. Núñez MEL. Registers and protocols (English). Hygia Enferm Rev Científica Col. [Internet] 2004 [cited Jul 11, 2019];(57):10-4. Available from: https://dialnet. unirioja.es/servlet/articulo?codigo $=3498721$

11. Penon CS, Linares AS. Protocolize nursing activities, Fundamental nursery (English). Rev ROL Enferm. [Internet] 2001 [cited Jul 11, 20192];24(1):67-76. Available from: https://dialnet.unirioja.es/servlet/ articulo?codigo $=2835264$

12. Piñeres MFC, Builes JAJ, Miranda RET. An integrated architecture for modeling computer systems for knowledge management in formative research. Rev Av En Sist E Informática. [Internet] 2011 Nov [cited Jul 11, 2019];8(3):157-63. Available from: https:// revistas.unal.edu.co/index.php/avances/article/ view/29776/30023
13. Cobb A. The Work Breakdown Structure. En: Leading Project Teams: The Basics of Project Management and Team Leadership [Internet]. 2a ed. Thousand Oaks: SAGE Publications; 2012 [cited Jul 11, 2019]. p. 37-60. Available from: http://sk.sagepub.com/books/leadingproject-teams-2e/n3.xml

14. Wang $H$, Jin J, Feng $X$, Huang $X$, Ling $Z$, Xiao $Z$, et al. Quality improvements in decreasing medication administration errors made by nursing staff in an academic medical center hospital: a trend analysis during the journey to Joint Commission International accreditation and in the post-accreditation era. Therap Clin Risk Manage. [Internet] 2015 Mar [cited Jul 11, 2019];11:393-406. Available from: https://www.ncbi. nlm.nih.gov/pmc/articles/PMC4354453

15. Alsulami Z, Conroy S, Choonara I. Medication errors in the Middle East countries: A systematic review of the literature. Eur ] Clin Pharmacol. [Internet] 2013 Oct [cited Jul 11, 2019];69(4):995-1008. Available from: https:// www.ncbi.nlm.nih.gov/pmc/articles/PMC3621991/.

16. Rogers JW, Fleming M, Tipton J, Ward A, Garey KW, Pitman EP. Investigating inpatient medication administration using the theory of planned behavior. Am J Health-Syst Pharm AJHP Off ] $\mathrm{Am}$ Soc Health-Syst Pharm. [Internet] 2017 Dec [cited Jul 11, 2019];74(24):2065-70. Available from: https://academic.oup.com/ajhp/ article/74/24/2065/5102731

17. Corral Y. Validity and reliability of the instruments to collect data. Rev Cienc Educ. [Internet] 2009 Feb [cited Jul 11, 2019];19:228-47. Available from: http:// servicio.bc.uc.edu.ve/educacion/revista/n33/art12.pdf 18. Escudero E, Ben-Azul MA, Dominguez-Cancino K. Clinical simulation and patient safety: integration into the nursing curriculum. Sci Med. [Internet]. 2018 Jan 26 [cited Jul 11, 2019];28(1):28853. Available from: http://revistaseletronicas. pucrs.br/scientiamedica/ojs/ index.php/scientiamedica/article/view/28853

19. Osuna B, Manuel J, Cabero Almenara J. The Use of Expert Judgment for Assessing ICT: the Coefficient of Expert Competence. [Internet]. 2013 Feb [cited Jul 11, 2019]. Available from: https://idus.us.es/xmlui/ handle/11441/24562

20. Ramírez MC, Cepena MCM. Refining a Tool for the Selection of Experts in Educational Research. REDIE. [Internet]. 2012 Jan [cited Jul 11, 2019];14(2):167-9. Available from: http://www.scielo.org.mx/scielo.php? script=sci_arttext\&pid $=$ S1607-40412012000200012

21. Corvetto M, Bravo MP, Montaña R, Utili F, Escudero E, Boza $C$, et al. Simulation in medical education: a synopsis. Rev Médica Chile. 2013 Jan [cited Jul 11, 2019];141(1):70-9. Available from: https://scielo.conicyt.cl/scielo.php? script=sci_arttext\&pid=S0034-98872013000100010 
22. Vega P, López L. Ethics in clinical research (English) [Internet]. Rev Chi Anest. 2014 [cited Jul 11, 2019]; 43: 361-7 Available from: http://revistachilenadeanestesia. cl/etica-en-la-investigacion-clinica/

23. Cruz CDL, Maribel K. Creation and validation of a nursing assessment instrument in palliative care needs of the pediatric patient of the National Institute of Child Health in 2017 (English). Univ Nac Mayor San Marcos [Internet]. 2018 [cited Jul 11, 2019]; Available from: http://cybertesis.unmsm.edu.pe/handle/cybertesis/7551 24. Almeida MA, Pergher AK, Canto DF do. Validation of mapping of care actions prescribed for orthopedic patients onto the nursing interventions classification. Rev. LatinoAm. Enfermagem. [Internet]. 2010 Feb [cited Jul 11, 2019];18(1):116-23. Available from: http://www. scielo.br/scielo.php?script=sci_arttext\&pid=S0104$11692010000100018 \&$ Ing=en\&tIng=en

25. Lima-Rodríguez JS, Lima-Serrano M, Ponce-González JM, Dolores Guerra-Martín M. Design and content validation of rubrics for assessing practical competencies in nursing students. Educ Médica Super. [Internet]. 2015 Mar [cited Jul 11, 2019];29(1):119-33. Available from: http://scielo.sld.cu/scielo.php?script=sci_arttext \&pid=S0864-21412015000100012

26. Müggenburg $C$, Robles $R$, Valencia $A$, Guillén $M$ del $\mathrm{CH}$, Olvera S, Rosas AR. Evaluation of the patient's perception on the communication behavior of the nursing personnel: design and validation in the Mexican population. Salud Ment. [Internet]. 2015 Jul [cited Jul 11, 2019];38(4):273-80. Available from: http:// www.scielo.org.mx/scielo.php?script=sci_arttext\&pid =S0185-33252015000400273

27. Morales-Castillo FA, Hernández-Cruz MC, MoralesRodríguez MC, Landeros-Olvera EA, Validation and standardization of the instrument: Assessment of the provided caring behaviors in Mexican nurses. Enferm Univ. [Internet]. 2016 Mar [cited Jul 11, 2019];13(1):3-11. Available from: http://www. elsevier.es/es-revista-enfermeria-universitaria-400articulo-validacion-estandarizacion-del-instrumentoevaluacion-S1665706315000883

28. Almenara JC, Moro AI. Using the Delphi Method and its use in communication research and education. Edutec Rev Electrónica Tecnol Educ. [Internet]. 2014 Jun [cited Jul 11, 2019];(48):a272-a272. Available from: http://www.edutec.es/revista/index.php/edutec-e/article/ view/187

29. Bathish M, Wilson C, Potempa K. Deliberate practice and nurse competence. Appl Nurs Res. [Internet]. 2018 Apr 1 [cited Jul 11, 2019];40:106-9. Available from: https://www.sciencedirect.com/science/article/pii/ S0897189717305256
30. Cummings CL. Evaluating Clinical Simulation. Nurs Forum. (Auckl). [Internet] 2014 Jan [cited Jul 11, 2019]. 50(2):109-15. Available from: https://onlinelibrary. wiley.com/doi/abs/10.1111/nuf.12075

31. Breitkreuz KR, Dougal RL, Wright MC. How Do Simulated Error Experiences Impact Attitudes Related to Error Prevention? Simul Healthc J Soc Simul Healthc. [Internet]. 2016 Oct [cited Jul 11, 2019];11(5):32333. Available from: https://www.ncbi.nlm.nih.gov/pmc/ articles/PMC6154479/

32. Raurell-Torredà $M$, Olivet-Pujol J, Romero-Collado À, Malagon-Aguilera MC, Patiño-Masó J, Baltasar-Bagué A. Case-based learning and simulation: useful tools to enhance nurses' education? Nonrandomized controlled trial. J Nurs Scholarsh Off Publ Sigma Theta Tau Int Honor Soc Nurs. 2015 Jan [cited Jul 11, 2019];47(1):34-42. Available from: https://www.ncbi.nlm.nih.gov/pubmed/25346329

33. Cantrell MA, Franklin A, Leighton K, Carlson A. The Evidence in Simulation-Based Learning Experiences in Nursing Education and Practice: An Umbrella Review. Clin Simul Nurs. [Internet]. 2017 Dec [cited Jul 11, 2019];13(12):634-67. Available from: https://www. nursingsimulation.org/article/S1876-1399(17)30051-8/ abstract

34. Hardenberg J, Rana I, Tori K. Simulation Exposure Improves Clinical Skills for Postgraduate Critical Care Nurses [Internet]. Clin Simul Nurs. 2019 Mar [cited Jul 11, 2019];28:39-45. Available from: https://www.sciencedirect.com/science/article/pii/ S1876139918300926

35. Tabassum N, Saeed T, Dias J, Allana S. Strategies to Eliminate Medication Error among Undergraduate Nursing Students. Int ] Nurs Educ. [Internet] 2016 Jan [cited Jul 11, 2019];8:167. Available from: http://connection. ebscohost.com/c/articles/112739835/strategieseliminate-medication-error-among-undergraduatenursing-students

36. Gonzalez L, Kardong-Edgren S. Deliberate Practice for Mastery Learning in Nursing. Clin Simul Nurs. [Internet] 2017 Jan [cited Jul 11, 2019];13(1):10-4. Available from: https://www.nursingsimulation.org/article/S18761399(16)30080-9/abstract.

37. Balzer F, Hautz WE, Spies C, Bietenbeck A, Dittmar M, Sugiharto $F$, et al. Development and alignment of undergraduate medical curricula in a web-based, dynamic Learning Opportunities, Objectives and Outcome Platform (LOOOP). Med Teach. [Internet] 2016 Apr [cited Jul 11, 2019];38(4):369-77. Available from: https://www.tandfonline.com/doi/abs/10.3109/014215 9X.2015.1035054?journalCode $=$ imte20

38. Aggarwal R, Mytton OT, Derbrew M, Hananel D, Heydenburg $M$, Issenberg $B$, et al. Training and simulation for patient safety. Qual Saf Health Care. [Internet]. 2010 
Aug [cited Jul 11, 2019];19 Suppl 2:i34-43. Available from: https://www.ncbi.nlm.nih.gov/pubmed/20693215 39. Jarvill M, Jenkins S, Akman O, Astroth KS, Pohl C, Jacobs PJ. Effect of Simulation on Nursing Students' Medication Administration Competence. Clin Simul Nurs. [Internet] 2018 Jan [cited Jul 11, 2019];14:3-7. Available from: https://www.nursingsimulation.org/ article/S1876-1399(17)30100-7/fulltext.

40. Anjos K, Santos V, Almeida O, Boery R, Boery E. Perception of nursing graduates about methodologies and strategies for teaching- learning. Rev Enferm UFPE Line. [Internet] 2013 Aug [cited Jul 11, 2019];7:5120-8. Available from: https://periodicos.ufpe.br/revistas/ revistaenfermagem/article/view/11783

41. INACSL Standards of Best Practice: Simulation SM Facilitation. Clin Simul Nurs. [Internet] 2016 Dec [cited Jul 11, 2019];12:S16-20. Available from: https://www. nursingsimulation.org/article/S1876-1399(13)00112-6/ abstract Creative Commons (CC BY).

This license lets others distribute, remix, tweak, and build upon your work, even commercially, as long as they credit you for the original creation. This is the most accommodating of licenses original creation. This is the most accommodating of licenses
offered. Recommended for maximum dissemination and use of licensed materials. 